\title{
Управление длительностью суб-импульсной структуры двухмасштабных импульсов
}

\author{
А.В. Иваненко ${ }^{1, *}$, Б.Н. Нюшков ${ }^{1,2}$, С.В. Смирнов ${ }^{1}$, Д.Б. Луценко ${ }^{1}$, \\ М.Г. Дятлов ${ }^{1}$, С.М. Кобцев ${ }^{1}$ \\ ${ }^{1}$ Новосибирский государственный университет \\ ${ }^{2}$ Новосибирский государственньй технический университет \\ "E-mail: ivanenko.aleksey@gmail.com
}

DOI: 10.31868/RFL2020.183-184

Шумоподобные импульсные кластеры генерируются во многих волоконных лазерах с синхронизацией мод, особенно в волоконных лазерах со сравнительно длинными резонаторами [1-3]. Интерес к таким кластерным фемтосекундным или пикосекундных импульсам (иногда называемым двухмасштабными импульсами) обусловлен тем, что они могут обеспечить рекордно высокие энергии и средние значения мощность излучения непосредственно от волоконных задающих генераторов [4-5] без дополнительного усиления, а также относительно высокую эффективность нелинейно-оптических преобразований [6-8]. Однако управление параметрами таких импульсов - формой и длительностью огибающей, характеристиками суб-импульсного заполнения - является непростой задачей из-за нетривиальной стохастической структуры внутриимпульсного электромагнитного поля. Ранее в работах $[9,10]$ была продемонстрирована возможность управления степенью когерентности таких волновых импульсных кластеров и влиянию степени когерентности на эффективность нелинейно-оптических преобразований.

В данной работе впервые представлены результаты исследования влияния ширины внутрирезонаторного спектрального фильтра на структуру двухмасштабных импульсов. Показано, что в лазере с активной синхронизацией мод увеличение ширины спектрального фильтра уменьшает длительность субструктур двухмасштабных импульсов, не изменяя при этом длительности огибающей импульсного цуга. Впервые продемонстрировано управление средней длительностью субимпульса (от 1,4 пс до 170 фс) с помощью спектральной селекции.

Влияние спектрального фильтра исследовалось в сверхдлинном кольцевой полностью волоконном лазера с активной синхронизацией мод за счёт синхронной накачки с частотой равной частоте обхода резонатора. Схема волоконного лазера представлена на рисунке 1.

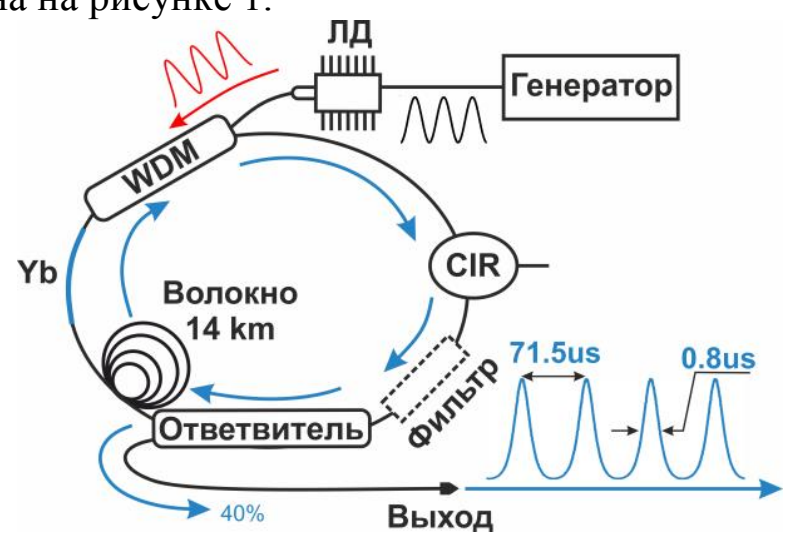

Рис. 1. Схема волоконного лазера. ЛД - лазерные диоды накачки, WDM - волоконный мультиплексор для объединения длин волн накачки и излучения генерации, $\mathrm{Yb}$ - активное волокно, легированное ионами иттербия. 
При настройке частоты модуляции лазерного диода накачки на фундаментальную частоту обхода резонатора лазер генерировал импульсы с длительнстью огибающей 800 нс.

В лазере была предусмотрена возможность смены оптических фильтров. Влияние спектральной фильтрации оценивалось по длительности центрального пика автокорреляционной функции (АКФ) импульсов, которая соответствует средней длительности суб-импульсов. Пик в центре АКФ обусловлен биением (наложением не связанных или слабо связанных по фазе) различных спектральных компонент, вышедших в генерацию и формирующих стохастическое субимпульсное заполнение [11]. Таким образом, длительность этого пика обратнопропорциональна ширине генерируемого спектра, и спектральная фильтрация приводит к сужению спектра и увеличению длительности суб-импульсов.

В зависимости от ширины используемого фильтра или его отсутствия длительность АКФ суб-импульсов варьировалась от 1,4 пс до 170 фс (рис. 2). При этом длительность огибающей импульсных цугов оставалась всегда 800 нс.
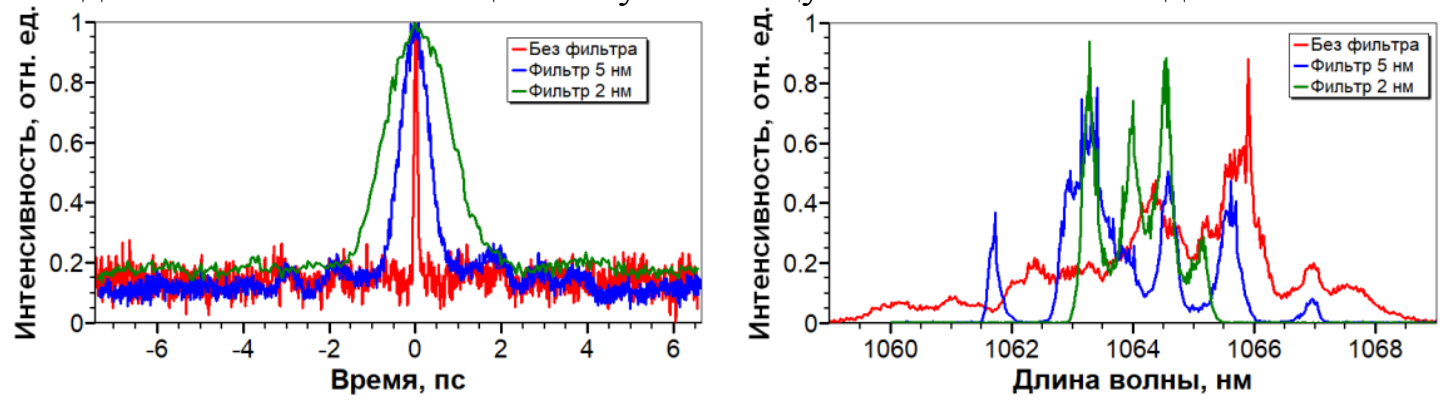

Рис. 2. Центральные части автокорреляционных функций и совмещенные оптические спектры двухмасштабных импульсов, полученные при разной полосе пропускания внутрирезонаторных фильтров (центральная длина волны спектра импульсов без фильтрации составляет 1030 нм).

Полученные результаты хорошо согласуются с моделью, изложенной в [11]. При увеличении ширины фильтра в 2.5 раза (с 2 нм до 5 нм) в соответствии с этой моделью должно происходить уменьшение характерного времени осцилляций (длительности суб-импульсов) в 2.5 раза - с 1.7 пс до 680 фс. В эксперименте было получено 700 фс. Полученные экспериментальные результаты хорошо согласуются с теоретическими представлениями.

Данный метод открывает новые перспективы по управлению двухмасштабными импульсами и их применения в различных областях науки и техники.

Работа выполнена при поддержки РФФИ (18-32-20021) и Министерства образование и науки РФ (FSUS-2020-0036).

\section{Литература}

[1] Smirnov S., et al., Optics express 20.24, 27447-27453 (2012).

[2] Kobtsev S., et al., Optics Express 17.23, 20707-20713 (2009).

[3] Pan, Ci-Ling, et al, InTech, 2016.

[4] Ivanenko A. et al., Optics express 24.6, 6650-6655 (2016).

[5] Fedotov, Y. S., et al., Optics express 22.25, 31379-31386 (2014).

[6] Smirnov S. et al., Optics Express 22.1, 1058-1064 (2014).

[7] Kobtsev S, et al., Optics express 22.17, 20770-20775 (2014).

[8] Xia H., et al., Applied optics 54.32, 9379-9384 (2015).

[9] S. Kobtsev, et al,. Laser Phys. Lett., v. 15, No. 4, 045102 (2018).

[10] S. Kobtsev, et al., Proc. SPIE, v. 10902, 109021F (2019).

[11] S. Kobtsev, et al., Chapter 4 in book "Fiber Laser" (ed. M.C.Paul), p. 69-88, InTech, 2016, ISBN: 978-953-51-4615-5. 